\title{
A CASE REPORT -UTERINE RUPTURE AFTER PREVIOUS CAESAREAN SECTION
}

\author{
Dr.Amrita Kishor Jeswani \\ Post Graduate Student, \\ Department of Obstetrics and Gynaecology, \\ Dy Patil Medical College, \\ Kolhapur, \\ Maharashtra
}

\author{
Dr.Suman Saurabh Gupta \\ Post Graduate Student, \\ Department of Pathology, \\ Dy Patil Medical College, \\ Kolhapur, \\ Maharashtra
}

\author{
Dr.Rohit Kishor Jeswani \\ Consultant MS Obstetrics and Gynaecology, \\ Karanja, \\ Maharashtra
}

Article DOI: https://doi.org/10.36713/epra6415

\begin{abstract}
Uterine rupture though a rare complication is life threatening for mother as well as baby. The commonest cause for rupture of a gravid uterus is previous caesarean section. It is important that the risk of rupture of uterus is explained to the pregnant female who has undergone previous caesarean section. The symptoms with which the patient presents can be subjective and vague like pain in abdomen or of acute abdomen. The patient can also come with objective findings like non-reassuring fetal status and loss of fetal station. With previous caesarean section it is important to be vigilant throughout the pregnancy especially in third trimester. It is also imperative that the patient should be educated about the signs and symptoms of rupture uterus so that timely intervention can be done to save the life of mother and the baby. In the present case study, the USG scan revealed that the placenta had shifted and was covering the internal os from fundoposterior position along with the shift of baby from cephalic presentation to transverse lie. Hence these case was a suspicious of rupture uterus which causes change in lie as well as presentation of baby.
\end{abstract}

\section{INTRODUCTION}

With increase in rate of caesarean section worldwide, the risk of rupture of uterus in subsequent pregnancies is increased.(1) Uterine rupture is defined as a full-thickness separation of the uterine wall and the overlying serosa and is associated with clinically significant uterine bleeding, fetal distress, protrusion or expulsion of the fetus and/or placenta into the abdominal cavity, Need for prompt cesarean delivery, Uterine repair or hysterectomy.(2, 3) Previously scarred uterus due to caesarean section is one of the most common and greatest risk factors for uterine rupture of a gravid uterus.(4) The WHO multi-country survey has reported incidence of uterine rupture due to caesarean section globally as
$0.5 \%$ while for low HDI (Human Development Index) countries like India it is $1 \%$. (1) A study conducted in Raipur, India stated that the incidence of uterine rupture with previous caesarean section was $1.69 \%$.(5) According to a literature review on uterine rupture in developing countries, the proportion of women with prior CS or uterine scar among women who had uterine rupture was up to $64 \%$ (6) Though a rare complication uterine rupture is associated with severe maternal and neonatal morbidity and mortality.(2) Other associated risk factors are trauma due to domestic violence, road traffic accidents and obstetric manures like internal version, breech extraction and Iatrogenic risk factors such as medical induction or oxytocin stimulation 
(augmentation of labour), intrauterine surgeries, uterine anamolies, grand multiparity, abnormal placentation, prolonged labour, obstructed labour, macrsomia, cocaine abuse, congenital uterine anamoly, inter-pregnancy interval of less than 6 months etc. Most common rupture site in gravid uterus is corneal area and uterine fundus. $(7-13)$

\section{CASE STUDY}

A 24 year old G2P1L1 female with 9 months of amenorrhea came with the complaints of pain in abdomen since morning. The pain was insidious in onset, gradually progressive with no relieving and aggravating factors. There was no history of fever, cold and cough, no bowel and bladder complaints. There was no history of any major illness like Diabetes Mellitus, Hypertension, Bronchial Asthma or Tuberculosis. She had delivered a female child 18 months back by a lower section caesarean section which was done in view of oligohydramnios. She is married since 3 years which is a non-consanguineous marriage and had conceived spontaneously in both the pregnancies. On examination her vitals were stable, the uterus was of term size and was irritable, fetal presentation was cephalic, but the fetal heart sounds were absent on auscultation and Doppler examination. The USG scan was carried out immediately which showed gestational age of 37 weeks 2 days with intrauterine fetal demise and oligohydramnios (AFI $-1.4 \mathrm{~cm}$ ). The scan showed that placenta was placed fundo-posteriorly with extension along right lateral wall and was completely covering the internal os. A scan done five days prior i.e. on 14/9/20 was normal with cephalic presentation and placenta was fundo-posterior of the infant. She refused to get admitted even after giving advised and later on came with pain in abdomen on 19/9/20 morning. On examinations her clinical findings suggested that the infant was in transverse lie, and the scan showed that the placenta was low lying covering internal os.

With these findings she was immediately taken to the operation theatre where she underwent caesarean section. The surgical findings were that the uterus was ruptured along the lines of previous scar. Also there was shift in position of placenta from fundo posterior to completely covering internal os and changed baby's position to transverse lie. Dead baby along with placenta were removed from the uterine cavity and the uterine wall was repaired.

\section{DISCUSSION}

Because of rare incidence and non-specific presentation uterine rupture is generally a missed diagnosis. The most common complaint of uterine rupture is the abdominal pain. The presence of just abdominal pain is a very non-specific symptom in a pregnant woman to reach to a differential diagnosis.
With this non-specific complaint, the clinical diagnosis of rupture uterus is not possible.

In the present case USG scan done in the previous week didn't show any abnormalities including the amniotic fluid index (11.1), fetal heart rate $(120 \mathrm{~b} / \mathrm{min})$ and placental position (fundoposterior). The patient presented with abdominal pain all of a sudden in the morning of $19^{\text {th }}$ September. The USG scan done immediately revealed that the placenta had shifted and was low lying covering the internal os from fundo-posterior position. Also baby got shifted to transverse lie from cephalic. Immediately caesarean section done, where rupture uterus along with dead baby was found.

This patient presented to the OPD with abdominal pain which is the common presentation of ruptured gravid uterus. Anubha Vidyarthi et al (14) reported that the patients with gravid uterine rupture presented with Abdominal tenderness (86\%) and Abdominal pain (77.2\%) followed by Palpable fetal part $(61.4 \%)$, Severe vaginal bleeding (7\%) and Shock $(68.4 \%)$.

Findings of Shu-Han You et al (13) were that the patients presented with complaints of nonreassuring fetal heart rate tracing (NRFHT) or acute abdominal pain. Revicky Vladimir et al (19) stated that most consistent early indicator of uterine rupture is the onset of a prolonged, persistent, and profound fetal bradycardia, other signs and symptoms of uterine rupture, such as abdominal pain, abnormal progress in labor, and vaginal bleeding.

Researches have reported previous caesarean section as one of the most common causes for uterine rupture (13,14,15). Shu-Han You et al (13) reported that the patients who suffered from uterine rupture, almost $80 \%$ of them had undergone previous uterine surgery followed by multiparity $(63.3 \%)$ and advanced maternal age. $33.33 \%$ women who suffered from uterine rupture had previous caesarean section, Al Zirqi et al (16) also reported similar findings that $36.4 \%$ women with uterine rupture hat history of previous caesarean section. Whereas Anubha Vidyarthi et al (14) reported that of all cases of uterine rupture $59.7 \%$ had undergone caesarean section.

In the present case study, the women's interdelivery period was 18 months. This is again a risk factor for uterine rupture in gravid uterus with previous caesarean section. Bujold et al (17) reported that the interdelivery interval shorter than 18 months was associated with a significant increase of uterine rupture (odds ratio [OR], 3.0; 95\% confidence interval $[\mathrm{CI}], 1.3-7.2)$. Similar findings were mentioned by Fitzpatrick et al (18) who stated that the women who had an interval of less than 12 months between their last caesarean section and their last menstrual period in their current pregnancy were having odds of 3.12 ( 95\% CI 1.62-6.02) for uterine rupture. 
No such similar case of suspicious rupture uterus which had led to change in lie and presentation of baby have been reported till date and hence further research is required. In present case study, risk factors for uterine rupture present were the previous caesarean section, less spacing between two pregnancies i.e. 18 months both were present in the patient.

\section{CONCLUSION}

Uterine rupture is an life threatening event in both mother and baby. The incidence of uterine rupture after caesarean section is almost double in developing countries like India than developed countries. This may be attributed to the lack of education and availability of professional care especially to high risk pregnancies like previous Caesarean section. A vigilant ANC care and appropriate education of mothers may lead to timely intervention and prevention in loss of infant and maternal life.

\section{REFERENCES}

1. Motomura K, Ganchimeg T, Nagata C, Ota E, Vogel $J P$, Betran AP, et al. Incidence and outcomes of uterine rupture among women with prior caesarean section: WHO multicountry survey on maternal and newborn health. Sci Rep. 2017;7:44093.

2. Ofir K, Sheiner E, Levy A, et al. Uterine rupture: risk factors and pregnancy outcome. Am J Obstet Gynecol. 2003;189:4.

3. Gerard G. Nahum, David Chelmow. Uterine rupture in pregnancy, 2012 updated 5 July 2018. Available at: http://reference.medscape.com/article/275854overview. Accessed 26 September 2020

4. Hofmeyr GJ, Say L, Gülmezoglu AM. WHO systematic review of maternal mortality and morbidity: the prevalence of uterine rupture. BJOG. 2005;112:1221-8.

5. Singh, A. \& Shrivastava, C. Uterine rupture: still a harsh reality! J. Obstet. Gynaecol. India. 65, 158161, doi: 10.1007/s13224-014-0551-2 (2015).

6. Berhe, $Y . \&$ Wall, L. L. Uterine rupture in resourcepoor countries. Obstet. Gynecol. Surv. 69, 695-707, doi: 10.1097/ OGX.0000000000000123 (2014).

7. Saglamtas $M$, Vicdan $K$, Yalcin $H$, Yilmaz $Z$, Yesilyurt H, Gokmen O. Rupture of the uterus. Int J Gynaecol Obstet. 1995;49(1):9-15. 3

8. Walsh CA, Baxi LV. Rupture of the primigravid uterus: A review of the literature. Obstet Gynecol Surv. 2007;62(5):327-34. quiz 353-4.

9. Henderson $C E$, Hana $R G$, Woroch $R$, Reilly $K D$. Short interpregnancy interval and misoprostol as additive risks for uterine rupture: A case report. J Reprod Med. 2010;55(7-8):362-4.

10. Nahum GG. Uterine anomalies. How common are they, and what is their distribution among subtypes? J Reprod Med. 1998;43(10):877-87.

11. Catanzarite V, Cousins L, Dowling D, Daneshmand S. Oxytocin-associated rupture of an unscarred uterus in a primigravida. Obstet Gynecol. 2006; 108(3 Pt 2):723-5.
12. Jones DE, Mitler LK. Rupture of a gravid bicornuate uterus in a primigravida associated with clostridial and bacteroides infection. J Reprod Med. 1978;21(3):185-8.

13. S.H.You, Y.L. Chang, C.F. Yen, Rupture of the scarred and unscarred graviduterus: outcomes and risk factors analysis, Taiwan. J. Obstet. Gynecol. 57 (2)(2018) 248-254

14. Vidyarthi A, Kumari S. Clinical study of cases of ruptured uterus in pregnancy. Int $J$ Reprod Contracept Obstet Gynecol 2018;7:253-6.

15. L. Posthumus and M. E. Donker, "Uterine rupture in a primigravid patient, an uncommon but severe obstetrical event: a case report," Journal of Medical Case Reports, vol. 11, no. 1, pp. 339-342, 2017.

16. Al-Zirqi I, Stray-Pedersen B, Forsen L, Vangen S. Uterine rupture after previous caesarean section. BJOG 2010;117:809-20.

17. Bujold E, Gauthier RJ. Risk of uterine rupture associated with an interdelivery interval between 18 and 24 months. Obstet Gynecol. 2010 May;115(5):1003-6. doi: 10.1097/AOG.0b013e3181d992fb. PMID: 20410775 .

18. Fitzpatrick KE, Kurinczuk JJ, Alfirevic Z, Spark P, Brocklehurst P, Knight M (2012) Uterine Rupture by Intended Mode of Delivery in the UK: A National Case-Control Study. PLoS Med 9(3): el001184. https://doi.org/10.1371/journal.pmed.1001184

19. Revicky V, Muralidhar A, Mukhopadhyay S, Mahmood T. A Case Series of Uterine Rupture: Lessons to be Learned for Future Clinical Practice. J Obstet Gynaecol India. 2012;62(6):665673. doi: 10.1007/s13224-012-0328-4 